Old Dominion University

ODU Digital Commons

\title{
Enabling Microblogging-Based Peer Feedback in Face-to-Face Classrooms
}

Tian Luo

Old Dominion University

Follow this and additional works at: https://digitalcommons.odu.edu/stemps_fac_pubs

Part of the Educational Methods Commons, and the Instructional Media Design Commons

\section{Repository Citation}

Luo, Tian, "Enabling Microblogging-Based Peer Feedback in Face-to-Face Classrooms" (2016). STEMPS Faculty Publications. 16.

https://digitalcommons.odu.edu/stemps_fac_pubs/16

This Article is brought to you for free and open access by the STEM Education \& Professional Studies at ODU Digital Commons. It has been accepted for inclusion in STEMPS Faculty Publications by an authorized administrator of ODU Digital Commons. For more information, please contact digitalcommons@odu.edu. 


\title{
Enabling microblogging-based peer feedback in face-to-face classrooms
}

\begin{abstract}
The purpose of this paper is to understand student interaction and learning in microblogging-based peer feedback sessions. The researcher examined through a case study how students interacted and provided peer feedback for each other when Twitter was enabled as a backchannel; students were also asked to report how they perceived their experience. The findings suggested that students participated actively in the microblogging-based peer feedback sessions. Although Twitter supported cognitive and corrective feedback, affective feedback was dominant. Student interaction on Twitter tended to be brief and involve low-level cognitive thinking in unguided, naturalistic learning contexts. Overall, students had a positive attitude toward using Twitter for peer feedback. Problems such as distraction and information overload were also identified.
\end{abstract}

Keywords: peer feedback; microblogging; classroom learning

\section{Introduction}

Providing feedback is one of the most powerful instructional strategies; indeed it is considered integral to the success of student learning (Gagne, Wager, \& Briggs, 1992; Merrill, 1983). As evidenced in multiple instructional design theories, feedback is an indispensible aspect in designing effective instruction. The process of feedback leads to a continuous and dynamic social interaction and results in improved learning outcomes (Gagne et al., 1992; Gropper, 1983; Merrill, 1983). Feedback can be provided by both instructors and students. Although instructor feedback tends to have higher accuracy of information, research shows that feedback provided by equal status peer learners as a form of peer assessment possesses its own unique attributes (Dippold, 2009; Ware \& O' Dowd, 2008). While traditional classroom feedback has its limitations in terms of time and space, the boom of web-based technologies has opened up mounting opportunities 
for peer feedback. Prior research consistently shows that web-based peer feedback methods have been advantageous as compared to traditional forms of feedback (Liu, Lin, Chiu, \& Yuan, 2001). The immediacy and flexibility afforded by web technologies has enabled learners to provide more frequent and timely feedback without the constraints of time and space (Augustsson, 2010; Everhart, 2006; Hall \& Dalgleish, 1999; Tsai, 2001).

\section{Peer feedback in web-based learning context}

Peer feedback is a form of formative peer assessment in which peer learners provide comments, advice, and suggestions to improve each other's work. Grounded in social constructivism theory (Vygosky, 1978), the adoption of peer feedback as an instructional strategy places great importance on learners' social interaction, which allows them to construct meaning in collaboration with others.

Researchers noted that web-based peer assessments outshine traditional paperbased forms of peer assessments in many ways. Web tools (a) ensure anonymity and therefore encourage students' genuine willingness to critique; (b) allow teachers to continuously monitor students’ progress; and (c) decrease the cost and logistical difficulties in administering paper-based peer assessment activities (Lin, Liu, \& Yuan, 2001). Over the years, web technologies have profoundly changed the process of peer assessment (Tseng \& Tsai, 2007). Recently, peer feedback has been increasingly provided in combination with a wide variety of Web 2.0 technologies (Tseng \& Tsai, 2007). In such learning environments, peer feedback can be delivered almost anytime or anywhere with little or no instructor presence.

Among existing web technologies adopted in classroom learning to promote feedback, microblogging tools have recently received much attention due to their ubiquitous, participatory and interactive nature. Microblogging tools such as Twitter 
allow a small amount of text-based content to be published on the user's profile page and immediately shared with open public Twitter users around the world (Luo \& Gao, 2012). Using Twitter as a backchannel (that is to say, a secondary string of online conversation about the primary instruction occurring at the front of the room), instructors can open up another conversation regarding the primary learning activity such as a lecture or a presentation. This allows simultaneous feedback and comments from a large number of students in face-to-face classrooms (Costa et al., 2008; Elavsky, Mislan, \& Elavsky, 2011). Although microblogging holds the potential to promote peer feedback, existing empirical research in this area has been limited. Therefore, the purpose of this research is to explore how students use microblogging to provide peer feedback, and to discover the characteristics of peer feedback in microbloggingsupported learning environments. Results from this study also offer insights on how to design and facilitate peer feedback activities using microblogging tools as well as other Web 2.0 interactive technologies.

\section{Frameworks for understanding peer feedback}

Researchers have developed various frameworks and criteria to understand and evaluate feedback. Nicol and Macfarlane-Dick (2006) proposed seven principles of good feedback practice, including that which "helps clarify aspects of a good performance" and "encourages teacher and peer dialogue around learning" (p. 205); these principles can often be achieved by peer feedback. Hattie and Timperley (2007) suggested understanding feedback by asking three major questions: Where am I going? How am I going? and Where to next? Answering these questions help learners identified gaps between desired and actual performance as well as provide remediation.

Chi (1996) differentiated three kinds of feedback based on their content: (a) corrective feedback: statements that point out errors or correct mistakes directly; (b) 
didactic feedback: lengthy statements to explain students' errors; and (c) suggestive feedback: more subtle advisory statements serving to redirect students' thinking. Nelson and Schunn (2009) proposed to classify feedback into cognitive and affective categories. Affective feedback emphasizes the emotional appeal of feedback, which often appears in the form of praise and compliments to enhance students' motivation.. In contrast, cognitive feedback focuses on providing specific comments or summarizations, identifying problems, and offering solutions or suggestions.

Recently, new conceptualizations of desired feedback have received much attention. For example, Hounsell (2007) proposed the notion of sustainable feedback, meaning to (a) involvestudents in dialogues about learning that raise their awareness of quality performance; (b) facilitatefeedback processes through which students are stimulated to develop capacities to monitor and evaluate their own learning; and (c) enhance student capacities for ongoing lifelong learning by supporting student development of skills for goal setting and study planning (Carless, Salter, Yang, \& Lam, 2011, p. 405). Constructive feedback that derived from constructive criticism is also extolled by educators and practitioners (du Toit, 2012; Duffy, 2013; Hendry, Bromberger, \& Armstrong, 2011). This type of feedback emphasizes the capacity for change through reference to specific problematic behaviours and acceptable standards or performance; in the form of a valid, well-reasoned, often negative evaluative opinion provided using a friendly, non-offensive tone. Research shows that constructive feedback often takes three forms: (a) criticisms, (b) questions, and (c) suggestions for improvements (Brookhart, 2008). All the above-mentioned frameworks serve as foundations to understand the microblogging-based peer feedback and to guide the development of coding schemes in this study.

\section{Research questions}


Despite microblogging's growing popularity in enhancing classroom conversations, this particular use of Twitter to promote peer feedback in student presentations has not been investigated in previous research. Understanding how learners behave and interact in such Twitter-mediated environments is of growing importance to develop appropriate pedagogical strategies to promote peer feedback in classrooms. This study seeks to examine the process of students using Twitter to provide peer feedback and to determine the nature of Twitter-mediated classroom interactions during the peer feedback session and what types of peer feedback is better supported by Twitter. The following research questions are used to guide this study:

1. How did students interact and participate during the microblogging-based peer feedback sessions?

2. How did students perceive their experience of microblogging-based peer feedback sessions?

\section{Methods}

\section{Research design}

The adopted methodological approach is a case study. Case studies embrace a multi-dimensional approach to analysis, especially through the use of multiple sources of evidence (Yin, 2008). A combination of qualitative and quantitative methods is often found in case studies and serves the best purposes, as the strengths and weaknesses of qualitative and quantitative methods are essentially complementary (Yin, 2008).

\section{Participants}

Participants were 25 college students aged 18 to 22 who were enrolled in an undergraduate level course concerning the use of Web 2.0 tools in education; among whom 14 were female and 11 were male. All these students had majored in education 
with a specific disciplinary focus. The majority of students (23 of 25) had a twitter account prior to the class and only one did not have a smartphone.

\section{Settings}

The course was offered at a Midwestern university as a required course for all education majors on various levels. The major purpose of this course was to acquaint students with technology applications commonly found in educational settings. The expected learning outcomes were for students to use a wide variety of emerging Web 2.0 technologies to develop or enhance classroom instruction.

\section{Procedures}

Twitter-mediated peer feedback sessions were implemented in two 1.5-hour face-to-face classroom sessions in spring 2013. Students watched a brief demonstration of Twitter and performed hands-on activities prior to the implementation. The primary activity was a group project presentation, during which Twitter was adopted as a backchannel to provide feedback and comments concurrently. The presentation required students to teach a technology application for classroom educational use. Students were not given specific instructions on what types of feedback were desired. No designated time period was allocated as all tweets were posted simultaneously with the presentations. The instructor periodically reviewed the tweets upon the completion of each group presentation. Students' tweets were collected after the implementation. A post-class online survey was administered electronically through email and responses were collected within one week of the implementation.

\section{Data analysis}

\section{Student tweets}


Student posts on Twitter served as a key data source. These postings were analyzed from both quantitative and qualitative dimensions to provide insights on the nature of student interactions and Twitter-mediated peer-feedback. The quantitative dimensions included (a) the number of students who participated; (b) the average number of messages each student posted; and (c) the average word length of each post.

Content analysis was conducted to analyze student tweets. Grounded theory approach was adopted as it provides systematic means to develop codes and categories based on the data (Charmaz, 2006; Glaser \& Strauss, 1967). Initially, two researchers conducted a screening of all tweets and filtered out those that were not considered peer feedback. This resulted in two major categories: feedback tweets versus non-feedback tweets. Secondly, researchers developed a coding scheme to further categorize peer feedback tweets based on a modification frameworks developed by Chi (1996) and Nelson and Schunn (2009). Lastly, constructive feedback was selected from the peer feedback pool and further categorized into (a) criticisms, (b) questions, and (c) suggestions based on their different forms. Two researchers coded the tweets independently and agreements were achieved through discussion. A coding scheme including all categories and example tweets are shown in Table 1.

Table 1 A coding scheme for student tweets

\begin{tabular}{llll}
\hline Categories & $(1)$ & Definitions & Tweet Examples \\
\hline Non- & $(2)$ & Tweets that are not & last class of the semester!!!!! where \\
feedback & pertinent to student & did the time go?! \\
& presentation topics. & Last \#EDCT2030 class of the \\
& $(3)$ & semester!!! \\
& & Tweets that are not & \#edct2030 presentation complete!
\end{tabular}




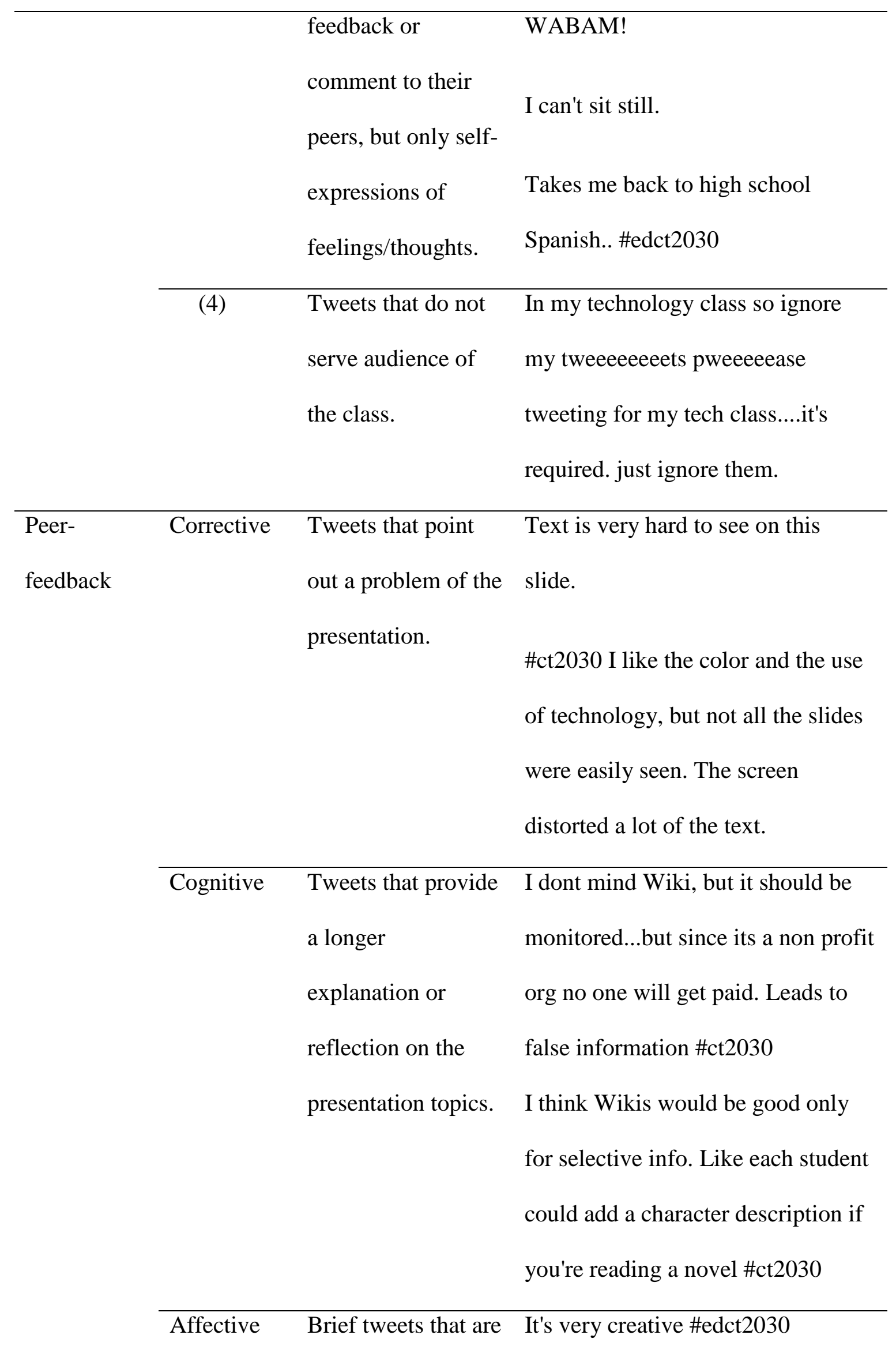




\begin{tabular}{|c|c|c|c|}
\hline & & $\begin{array}{l}\text { encouraging and } \\
\text { motivational, } \\
\text { typically in the } \\
\text { form of praise or } \\
\text { compliments }\end{array}$ & $\begin{array}{l}\text { @edct2030 cool prezi } \\
\text { Great job! \#edct2030 }\end{array}$ \\
\hline $\begin{array}{l}\text { Constructive } \\
\text { feedback }\end{array}$ & Criticisms & $\begin{array}{l}\text { Overt negative } \\
\text { comments that }\end{array}$ & $\begin{array}{l}\text { \#ct2030 there is a couple problems } \\
\text { with viewing the text on some of } \\
\text { the slides } \\
\text { I don't think I would ever use this in } \\
\text { my class.. \#ct2030 }\end{array}$ \\
\hline & Questions & $\begin{array}{l}\text { Doubts, concerns, } \\
\text { inquiries in the } \\
\text { form of questions }\end{array}$ & $\begin{array}{l}\text { Would the best use for a wiki be } \\
\text { one that is isolated to a certain class } \\
\text { or even school? \#ct } 2030 \\
\text { \#ct } 2030 \text { how do u think teachers } \\
\text { should introduce wiki's } 2 \text { their } \\
\text { students? If they can b edited by } \\
\text { every1 how do they no whats true } \\
\text { or false }\end{array}$ \\
\hline & Suggestions & $\begin{array}{l}\text { Advice for } \\
\text { improvements }\end{array}$ & $\begin{array}{l}\text { It would be easier on the eyes if text } \\
\text { were not black. \#ct } 2030 \\
\text { It would be better to incorporate } \\
\text { second life into other types of } \\
\text { learning contexts. \#ct2030 } \\
\text { \#edct } 2030\end{array}$ \\
\hline
\end{tabular}


Surveys

A survey was conducted to examine students' perceptions about their experience in the Twitter-mediated peer feedback sessions. The survey consisted of five Likertscale items on the effectiveness of Twitter integration on varying dimensions and two open-ended questions that asked students to justify their ratings by providing additional comments about their interactions and classroom experience using Twitter.

\section{Results}

During the two Twitter-mediated feedback sessions, a total of 165 tweets were posted by students. Twenty out of 25 students actively participated in the microblogging activity by posting tweets. On average, each student had approximately eight tweets (mean= 8.25, $\mathrm{SD}=2.63$ ). Due to the 140-character limit, the average length of each post was approximately 12 words/60 characters.

Content analysis results show that $70 \%$ (115 out of 165 tweets) of student interaction on Twitter was of a feedback nature. Table 2 presents a breakdown of different types of student feedback. Since the peer feedback sessions were implemented with little structure and guidance, $30 \%$ of tweets were postings irrelevant to student presentation topics. This result concurs with previous research finding that guided elements are necessary to ensure the relevancy of tweets and quality of student learning on the microblogging platform (Holotescu \& Grosseck, 2009; Luo \& Gao, 2012). The analysis of the $70 \%$ of relevant tweets shows that students were able to use Twitter to pinpoint problems and errors as soon as they found them in the presentations. For example, issues such as too much text on the screen or difficulty in viewing the pictures were immediately brought up in student tweets. More importantly, student tweets showed that students were engaged in cognitive reflection of learning topics covered in 
the presentations. For instance, when students discussed the credibility issue of information on Wikipedia, five students tweeted about their experience using Wikipedia and casted doubt on information with unconfirmed or unauthentic sources. It is evident that the majority of tweets (61.7\%) were affective in nature. Students were much more inclined to provide brief affective feedback such as "good job,” "well-done,” or "I like your presentation,” which may be due to the nature of Twitter as a medium for brief messages, the uncontroversial characteristic of student presentations, as well as the overall encouraging classroom culture in North America. Some researchers argued that affective feedback in the form of praise representing affective aspects of learning is commonly considered as good feedback practice in educational settings (Brookhart, 2008; Lu \& Law, 2012), but this type of uncritical peer feedback is criticized because it hardly involves cognitive thinking and is only a manner of showing support or agreement (Nilson, 2003).

Table 2 Types of student tweets

\begin{tabular}{lcc}
\hline Categories & Number & Percentage (\%) \\
\hline Corrective & 13 & 11.3 \\
Cognitive & 31 & 27.0 \\
Affective & 71 & 61.7 \\
Total & 115 & $100 \%$
\end{tabular}

Among all feedback tweets, 32.2\% (37 out of 115) were constructive peer feedback that emphasized problematic behaviors and made explicit reference to standards or performance. Table 3 presents a breakdown of different forms of student constructive feedback. Since constructive feedback is deemed as a higher-level quality 
feedback (Duffy, 2013; Hendry et al., 2011), this proportion, 32.2\%, found in microblogging-based peer feedback activity with little intervention from the instructor appears to be desirable. All these constructive feedback tweets were immediately posted, as problems were spotted during the course of the peer feedback activity; therefore, the feedback was prompt, specific, and contextualized. Among all forms of constructive feedback, the majority of tweets (48.6\%) were criticisms that briefly pointed out specific issues or raised disagreements as students were viewing the presentation. Many of these criticisms targeted technical issues such as "texts were not clearly seen," and "colors were blurred." Some tweets questioned the appropriateness of the presentation content; for example, "topic might be too advanced for 5th graders." The question type of constructive feedback seems to be well-supported and it tended to be much lengthier in words. For example, many students cast doubts on the credibility of information provided by Wikis using question forms, e.g., "How can Wiki's restrict the editing on the content area to make sure that all information presented is factual?" In contrast, the suggestion type of constructive feedback seemed to be minimal. Most of the suggestion tweets were also focused on addressing the technical issues. Aside from the fact that student presentations seldom led to any necessary solutions or suggestions, students may not have had the needed time span to provide a solution for problems that they noted during the presentations.

Table 3 Forms of constructive feedback

\begin{tabular}{lcc}
\hline Categories & Number & Percentage (\%) \\
\hline Criticisms & 18 & 48.6 \\
Questions & 11 & 29.7 \\
Suggestions & 8 & 21.6 \\
\hline
\end{tabular}


The means and standard deviations of Likert-scale survey items are presented in Table 4. Overall, students had a pleasant experience in the Twitter-mediated peer feedback sessions as they provided positive ratings across all items in this survey. Students responses indicated that being able to express their own understanding and interact with their classmates were the two major benefits of using Twitter as a backchannel. These results concur with findings from the open-ended questions. Six students recognized that they were able to have their own voice because of the virtual participation venue enabled by Twitter. Consistent with these students' comments, the survey item "The Twitter integration during the student presentation helped me to effectively express my own understanding" received the highest rating. Students also noted that the Twitter add-on was an engaging learning experience because "it allowed everyone to speak their mind." Moreover, using Twitter improved the timeliness and immediacy of peer feedback. As one student explained, "We were able to type it as we noticed it rather than having to wait and maybe forget what we wanted to point out." Students also believed that the use of Twitter enhanced the interactivity of the classroom. Six students commented that the Twitter backchannel was a flexible, fun and effective way to interact with their peers during the presentations. One student wrote, "I was able to interact with the presentation as freely as I wished and also was able to see questions other students were asking."

Table 4 Student ratings on perceptions of Twitter-supported learning on a scale of 1 to 6

The Twitter integration during the student $\mathrm{N}$ Mean (SD) presentation helped me to effectively 
focus on learning the topic

interact with my classmates

express my own understanding

construct my own learning

interact with the instructor
25

25

25

25

25
$4.53(1.68)$

$4.74(1.70)$

4.79 (1.69)

4.63 (1.67)

4.47 (1.71)

1= strongly disagree; 2 = disagree; 3 = slightly disagree; 4 = slightly agree; 5 = agree; 6 =strongly agree

Students also shared their concerns of using Twitter as a backchannel for peer feedback. The most pressing concern is the issue of distraction and information overload, which can be drawn from the fact that the lowest rating among all survey items was "focus on learning the topic." Four students' responses in open-ended question indicated that it might hamper the quality of Twitter-mediated feedback. One student commented, "I did not think it was very effective because it was too chaotic and trying to keep up with what was being discussed became extremely confusing." Three students stated that an unfamiliarity with the microblogging-based learning environment was another resisting factor. As one student noted, "I didn't think this is effective but only because I am very unfamiliar with Twitter and it took me a while to get used to chatting back and forth instantly." Interestingly, one student also noted that this novel way of making comments using Twitter disrupted the traditional classroom etiquette. As she explained, "I didn't like how we were tweeting as they presented. I saw it as disrespectful." 


\section{Discussion}

Overall, students interacted and participated actively in the microblogging-based peer feedback activities and perceived their learning experience positively. The volume of participation as measured by number of participants (20 out of 25 students) is relatively sizable compared to a regular classroom where student have to raise hands one at a time to provide feedback. Through opening up a backchannel, students were provided with more opportunities for social interaction and peer support with one another. Using Nicol and Macfarlane-Dick's (2006) seven principles of good feedback practice as a parameter, it seems that adopting microblogging tools holds mounting potential to bring peer feedback closer to the quality standards. As Twitter-mediated feedback tends to be timely, specific, and personal, it can be used to help clarify what a good performance is and facilitate students' development of self-assessment in learning. The enabling of a backchannel allows student virtual participation and promotes dialogue around learning among teachers and peers, which helps deliver relevant and immediate information to students about their learning. Although most feedback was brief and affective in nature, this type of feedback seems to encourage positive motivational beliefs and self-esteem according to students' comments..

Although the backchannel setup allowed more room for participation, the quality and depth of such participation might be compromised in a naturalistic, unguided learning contexts. This finding corresponds to results from prior research, which reconfirms the critical role of instructional guidance and scaffolding in microbloggingbased learning (Holotescu \& Grosseck, 2009; Luo \& Gao, 2012). Therefore, prior training and hands-on activities focusing on using microblogging for educational purposes need to be prescribed, since students reported that much of their challenge in using microblogging came from their unfamiliarity with the technology and thus 
creating resistance to changing the traditional classroom culture. Equally important is that during the in-class learning activities, instructors need to provide specific scaffolds to guide student learning and minimize information overload caused by the explosive and disruptive nature of microblogging tools.

To improve the effectiveness of Twitter-mediated feedback, the notion of sustainable feedback should be reconsidered in the context of microblogging-based learning to make the peer feedback learning experience more valuable. As researchers noted, one of the deficiencies of feedback is that it is not always acted on in subsequent work (Chanock, 2000; Ellery, 2007). Students' peer feedback on Twitter is highly likely to have this sustainability issue (Hounsell, 2007). To address this issue, instructors can design follow-up activities, requiring students to review the tweets after the class and report the revisions and changes they made according to the feedback they received from their peers. These follow-up tasks can help leverage the positive effects of microblogging-based peer feedback and stimulate students to develop capacities in monitoring and evaluating their own learning.

\section{Conclusion}

With the prevailing use of Web 2.0 technology in education, educational practitioners have been increasingly enthusiastic about using microblogging to achieve varying educational goals and objectives (Gao et al., 2012). However, robust empirical research examining the effectiveness of microblogging-based instructional activities has been limited. As research of microblogging for education is still in its infancy, this study serves as one of the few exploratory studies that empirically investigate new possibilities of using microblogging to support peer feedback in classroom learning settings. 
Since this is an exploratory study with a small sample size, results from this research may not be generalizable in other contexts or with other population. Research conducted with a larger group is needed to test its applicability and generalizability. Future research using other rigorous methods such as experimental design is suggested to compare how students learn with and without the Twitter backchannel for peer feedback. Research may also examine the effects of different instructional strategies and determine what differing effects that would bring to the types of feedback.

\section{Reference}

Augustsson, G. (2010). Web 2.0, pedagogical support for reflexive and emotional social interaction among Swedish students. The Internet and Higher Education, 13(4), $197-205$

Brookhart, S. M. (2008). How to give effective feedback to your students. ASCD.

Carless, D., Salter, D., Yang, M., \& Lam, J. (2011). Developing sustainable feedback practices. Studies in Higher Education, 36(4), 395-407. doi:

$10.1080 / 03075071003642449$

Chanock, K. (2000). Comments on essays: Do students understand what tutors write? Teaching in Higher Education, 5(1), 95-105.

Charmaz, K. (2006). Constructing Grounded Theory: A Practical Guide through Qualitative Analysis. London: Sage Publications.

Chi, M. T. H. (1996). Constructing self-explanations and scaffolded explanations in tutoring. Applied Cognitive Psychology, 10, 33-49. 
Costa, C., Beham, G., Reinhardt, W., \& Sillaots, M. (2008). Microblogging In Technology Enhanced Learning: A Use-Case Inspection of PPE Summer School 2008. Paper presented at the Workshop on Social Information Retrieval for Technology Enhanced Learning.

Davies, Phil. 2009. Review and reward within the computerised peer-assessment of essays.

Dippold, D. (2009). Peer Feedback Through Blogs: Student and teacher perceptions in an advanced German class. ReCALL, 21, 18-36. doi:10.1017/S095834400900010X.

Du Toit, E. (2012). Constructive feedback as a learning tool to enhance students's selfregulation and performance in higher education. Perspectives in Education, 30(2), 32-40.

Duffy, K. (2012). Providing constructive feedback to students during mentoring. Nursing standard, 27(31), 50-60.

Elavsky, C. M., Mislan, C., \& Elavsky, S. (2011). When talking less is more: exploring outcomes of Twitter usage in the large ElexatainghaMedia and Technology, 36(3), 215-233. doi: 10.1080/17439884.2010.549828

Ellery, K. (2007). Assessment for learning: A case study using feedback effectively in an essay-style test. Assessment \& Evaluation in Higher Education, 33( 4), 421429.

Everhart, D. (2006). Evolving from course-centric to learning-centric: Portfolios, wikis, and social learning. Canadian Journal of University Continuing Education, 32(2), 133-146. 
Falchikov, N. (1995). Improving feedback to and from students. In P. Knight (Ed.), Assessment for learning in higher education (pp. 157-166). London: Kogan Page

Frost, J. \& Turner, T. (2005). Learning to Teach Science in the Secondary School (2nd Edition). London: Routledge Falmer.

Gagné, R. M., Wager, W. W. \& Briggs, L. J. (1992). Principles of instructional design (4th ed.), New York: Holt, Rinehart and Winston.

Gao, F., Luo, T., \& Zhang, K. (2012). Tweeting for learning: a critical analysis of research on microblogging in education published in 2008-2011. British Journal of Educational Technology, 43(5), 783-801.

Glaser, B. G., \& Strauss, A. L. (1967). The discovery of grounded theory: Strategies for qualitative research. Chicago: Aldine.

Greenhow, C., Robelia, B., \& Hughes, J. E. (2009). Learning, teaching, and scholarship in a digital age: Web 2.0 and classroom research: What path should we take now? Educational Researcher, 38(4), 246-259. doi:

10.3102/0013189x09336671

Gropper, G.L. (1983). A metatheory of instruction: A framework for analyzing and evaluating instructional theories and models. In Reigeluth, C.M. (Ed.).Instructional-design theories and models: An overview of their current status (pp. 37-53). New Jersey: Lawrence Erlbaum Associates.

Hall, R., \& Dalgleish, A. (1999). Undergraduates’ experiences of using the world wide web as an information resource. Innovations in Education and Training International, 36, 334-345. 
Hattie, J., \& Timperley, H. (2007). The power of feedback. Review of educational research, 77(1), 81-112.

Hanrahan, S. J., \& Isaacs, G. (2001). Assessing self- and peer-assessment: the students' views. Higher Education Research \& Development, 20(1), 53-70.

Hendry, G. D., Bromberger, N., \& Armstrong, S. (2011). Constructive guidance and feedback for learning: The usefulness of exemplars, marking sheets and different types of feedback in a first year law subject. Assessment \& Evaluation in Higher Education, 36(1), 1-11.

Hounsell, D. (2007). Towards more sustainable feedback to students. In D. Boud and N. Falchikov (Eds.) Rethinking assessment in higher education (pp.101-113). London: Routledge.

Kop, R., Fournier, H., \& Mak, J. (2011). A pedagogy of abundance or a pedagogy to support human beings? Participant support on massive open online courses. The International Review of Research In Open And Distance Learning, 12(7), 74-93. Retrieved from http://www.irrodl.org/index.php/irrodl/article/view/1041/2025

Laurillard, D. (2002). Rethinking university teaching: A conversational framework for the effective use of learning technologies (2nd ed.). London: Routledge Falmer.

Li, L., \& Steckelberg, A. L. (2006). Perceptions of Web-mediated Peer Assessment. Academic Exchange Quarterly, 10(2). Retrieved from http://rapidintellect.com/AEQweb/6apr3295l6.htm

Li, L., Liu, X., \& Steckelberg, A. L. (2010). Assessor or assessee: How student learning improves by giving and receiving peer feedback. British Journal of Educational Technology, 41(3), 525-536. 
Lin, S. J., Liu, E. F., \& Yuan, S. M. (2001). Web-based peer assessment: Feedback for students with various thinking-styles. Journal of Computer Assisted Learning, 17(4), 420-432. doi:10.1046/j.0266-4909.2001.00198.x

Liu, N. F., \& Carless, D. (2006). Peer feedback: the learning element of peer assessment. Teaching in Higher Education, 11(3), 279-290.

Liu, Z., Lin, S. J., Chiu, C-H., \& Yuan, S.M. (2001). Web-Based Peer Review: The Learner as both Adapter and Reviewer. IEEE Transactions on Education, 44(3), 246-251.

Luo, T., \& Gao, F. (2012). Enhancing classroom learning experience by providing structures to microblogging-based activities. Journal of Information Technology Education: Innovations in Practice, 11(1), 199-211.

Merrill, M.D. (1983). Component display theory. In C.M. Reigeluth (Ed.), Instructional design theories and models. Hillsdale, NJ: Lawrence Erlbaum.

Nelson, M. M., \& Schunn, C. D. (2009). The nature of feedback: how different types of peer feedback affect writing performance. Instructional Science, 37(4), 375-401.

Nicol, D. J., \& Macfarlane-Dick, D. (2006). Formative assessment and self-regulated learning: A model and seven principles of good feedback practice. Studies in higher education, 31(2), 199-218.

Tsai, C.-C. (2001). A review and discussion of epistemological commitments, metacognition, and critical thinking with suggestions on their enhancement in Internet-assisted chemistry classrooms. Journal of Chemical Education, 78, 970974. 
Tseng, S., \& Tsai, C. (2007). On-Line Peer Assessment and the Role of the Peer Feedback: A Study of High School Computer Course. Computers \& Education, 49(4), 1161-1174.

Vygotsky, L. (1978). Mind in society: The development of higher psychological processes. Cambridge, MA: Harvard University Press.

Ware, P., \& O'Dowd, R. (2008). Peer feedback on language form in telecollaboration. Language Learning \& Technology, 12(1), 43-63.

Yin, R. K. (2008). Case Study Research: Design and Methods. Thousand Oaks, CA: Sage Publications. 